\title{
A relação do Cebes com o PCB na emergência do movimento sanitário
}

\author{
The Cebes relationship with the PCB in the emergency of the sanitary \\ movement
}

André Teixeira Jacobina1

RESUMO Este artigo é o desdobramento de uma pesquisa cujo objetivo foi analisar a relação entre o movimento sanitário e os partidos políticos de matriz marxista no período correspondente à emergência do espaço social da Reforma Sanitária Brasileira (RSB) (1974-85). Este artigo se apoia nessa pesquisa e analisa a relação entre o Centro Brasileiro de Estudos de Saúde (Cebes) e o Partido Comunista Brasileiro (PCB). Recorre a artigos, documentos e entrevistas com lideranças da RSB, utilizando o referencial da sociologia reflexiva. Os resultados apontam a relação entre o Cebes e o PCB na formação de lideranças do movimento, entretanto, essa influência não significou a perda da autonomia da entidade no processo de luta pela RSB.

PALAVRAS-CHAVE Reforma dos serviços de saúde. Política de saúde. Sistemas políticos.

ABSTRACT This article is the unfoldment of a research whose objective was to analyze the relation between the sanitary movement and the political parties of Marxist matrix in the period corresponding to the emergence of the social space of the Brazilian Sanitary Reform (RSB) (197485). This article is based on this research and analyzes the relationship between the Brazilian Center for Health Studies (Cebes) and the Brazilian Communist Party (PCB). It uses articles, documents and interviews with leaders of the RSB, using the referential of reflexive sociology. The results point to the relationship between the Cebes and the PCB in the formation of leaders of the movement, however, this influence did not mean the loss of autonomy of the entity in the process of fight for the RSB.

KEYWORDS Health care reform. Health policy. Political systems.

1 Universidade Federal da Bahia (UFBA), Instituto de Saúde Coletiva (ISC) Salvador (BA), Brasil. andretj@terra.com.br 


\section{Introdução}

Os estudos sobre a emergência do movimento da Reforma Sanitária Brasileira (RSB) geralmente destacam o papel que o Centro Brasileiro de Estudos de Saúde (Cebes) desempenhou enquanto espaço que aglutinou as principais lideranças responsáveis pela formulação das propostas e estratégias que marcaram o movimento em seus primórdios. Tais estudos, entretanto, não destacam a relação entre esta organização e os partidos políticos em atividade - legal ou clandestina - no momento em que o movimento surgiu e, paulatinamente, ampliou-se, a ponto de desencadear mudanças no arcabouço jurídico e na configuração institucional do sistema público de saúde no País.

Escorel (2005), por exemplo, analisa a conjuntura em que emergiu o movimento sanitário e sua origem institucional, chamando a atenção para a importância dos Departamentos de Medicina Preventiva e Social (DMPs), lócus onde se desenvolveu um pensamento crítico sobre a situação de saúde da população, bem como sobre a política e a organização dos serviços de saúde vigentes no período autoritário, fundamentais para a ação política em defesa da democratização da sociedade brasileira, que contemplou a articulação de um conjunto de entidades.

A autora destaca a atuação do Cebes como uma "pedra fundamental, embora não a única, do movimento sanitário como movimento social organizado" (ESCOREL, 1998, P. 76), apontando, também, o movimento estudantil e o movimento de Renovação Médica (Reme) como vertentes estruturantes desse movimento (ESCOREL, 1998, P. 87). Seu trabalho, porém, não discute a relação entre o movimento sanitário e os partidos políticos, embora destaque o crescimento do Movimento Democrático Brasileiro (MDB) e a atuação dos partidos clandestinos, esses últimos, essencialmente, de matriz marxista, durante a ditadura militar, particularmente, na década de 1970 (ESCOREL, 1998).

Paim (2008), por sua vez, analisa a RSB como um fenômeno sócio-histórico que contempla diferentes momentos enquanto "ideia - proposta - projeto - movimento processo" (PAIM, 2008, P. 36), indicando como a ideia da RSB surge no movimento sanitário, vai ganhando forma e se inserindo na luta pela democratização do País. No que se refere à relação entre partidos e entidades desse movimento, o autor destaca, citando Rodrigues Neto, que apesar

de inicialmente contar com a influência de militantes do antigo Partido Comunista Brasileiro ( $P C B)$ e de reunir profissionais de saúde, - Cebes caracterizava-se pelo suprapartidarismo e pelo não corporativismo. (RODRIGUEZ NETO, 2003 APUD PAIM, 2008, P. 79),

característica que Paim atribui ao movimento sanitário como um todo.

A filiação de lideranças do movimento pela RSB a partidos políticos de esquerda, entretanto, é reconhecida em trabalhos recentes, como o de Vieira da Silva e Pinell (2013), que estudaram a gênese do espaço da saúde coletiva no Brasil e identificaram a vinculação dos seus fundadores a um amplo espectro político, com predomínio de partidos de esquerda, clandestinos no período autoritário, como o $\mathrm{PCB}$, o Partido Comunista do Brasil (PCdoB) e a Ação Popular (AP), apontando, inclusive, a presença de militantes desses partidos na direção de entidades da sociedade civil, como o Cebes e a Associação Brasileira de Saúde Coletiva (Abrasco) (VIEIRA-DA-SILVA; PINELL ET AL., 2013).

Nesse trabalho, os autores registram que existiram lideranças filiadas a partidos de esquerda e existiam integrantes do movimento, médicos e sociólogos de esquerda, que não estavam filiados a partidos, indicando a heterogeneidade de posições que foram aglutinadas em torno da luta pela 
RSB. Embora o objeto deste trabalho não tenha sido as relações entre os partidos políticos e o movimento da RSB, esse estudo assinala que a relação existia, sem analisar suas características, e foi justamente buscando detalhar a análise dessa relação que foi desenvolvida a pesquisa intitulada ' $O$ movimento da Reforma Sanitária Brasileira e sua relação com os partidos políticos de matriz marxista' (JACOBINA, 2016).

Este trabalho apresenta uma parte dos resultados dessa investigação, contemplando, especificamente, a pergunta acerca da relação do Cebes com o PCB no momento de sua emergência como organização. A escolha desse partido derivou da sinalização apontada no trabalho de Vieira da Silva e Pinell (2013), embora, como o próprio trabalho indique, outros partidos e tendências de matriz marxista tenham tido algum tipo de relação com o movimento sanitário, a exemplo do PCdoB e da Ação Popular, já citados.

A metodologia utilizada implicou revisão documental, especialmente dos editoriais das primeiras edições da revista 'Saúde em Debate' (RSD), bem como transcrições de entrevistas com lideranças do movimento sanitário que atuaram em sua gênese, tomando como base teórica uma revisão bibliográfica sobre a relação entre partidos e movimentos sociais que remontou ao debate entre Lenin e Rosa Luxemburgo (JACOBINA, 2016), bem como alguns conceitos extraídos da sociologia reflexiva de Bourdieu (1996B), que permitiram caracterizar as posições e os pontos de vista dos entrevistados. A análise das fontes orais beneficiou-se da revisão do trabalho de Alessandro Portelli (1981) acerca do uso de fontes orais em pesquisa histórica, especialmente a noção de 'memória dividida', que indica que a memória é mediada pelo tempo, pela ideologia e, como utiliza-se a sociologia reflexiva, pelas posições ocupadas pelos agentes ao longo do tempo.

Foram realizadas nove entrevistas. Os critérios de seleção dos agentes foram aqueles que ou militaram em movimentos sociais em saúde que estavam lutando pela RSB ou políticos que pudessem ter informações acerca da relação entre partidos e movimentos sociais em saúde. Além disso, foram utilizadas vinte e uma entrevistas entre aquelas realizadas por Vieira-daSilva, entre 2008 e 2011, com fundadores do Espaço da Saúde Coletiva, sendo que muitos deles participaram diretamente das articulações do movimento da RSB (VIEIRADA-SILVA, 2015). Cabe registrar que os entrevistados assinaram o Termo de Consentimento Livre e Esclarecido, autorizando a utilização de suas falas, porém, foi preservado o sigilo com relação à identidade de alguns deles, sendo identificados no texto apenas pelo número da entrevista.

\section{Conceitos básicos}

Considerando o papel do Cebes na articulação do movimento sanitário, busca-se revisar a literatura sobre movimentos sociais, sendo adotada a definição proposta por Charles Tilly, para quem:

Um movimento social consiste em um desafio sustentado aos detentores do poder em nome da população vivendo sob a jurisdição desses detentores do poder através de repetidas demonstrações públicas [...] incorpora interação contenciosa e envolve reivindicação mútua de demandas entre os desafiantes e os detentores de poder. (TILLY, 1993, P. 7).

Segundo este autor, esse conceito exclui outras formas de luta, como guerra civil, competição eleitoral e insurreições. Embora ativistas, às vezes, realizem ações diretas contra as autoridades, em geral, a ação dos movimentos sociais centra-se em formas indiretas de ação, pressionando os detentores do poder a realizar ações que respondam às suas demandas. Esse conceito é não apenas coerente com a sociologia de Bourdieu, que 
faz parte da tradição que entende o conflito como central nas relações humanas, mas se adequa bem ao movimento sanitário, já que esse tinha um conjunto de demandas que desafiavam os detentores do poder em uma conjuntura ditatorial, especialmente a demanda central por democratização da saúde, do Estado e da sociedade brasileira.

Já o conceito de partido político é encontrado em Weber, para quem:

A ação social típica dos 'partidos', em oposição àquela das 'classes' e dos 'estamentos' que não apresentam necessariamente este aspecto, implica sempre a existência de uma relação associativa, pois pretende alcançar, de maneira planejada, determinado fim seja este de natureza 'objetiva': imposição de um programa por motivos ideais ou materiais, seja de natureza 'pessoal': prebendas, poder e, como consequência deste, honra para seus líderes e partidários, ou, o que é o normal, pretende conseguir tudo isto em conjunto. (WEBER, 1999, P. 185).

Vale a ressalva de que mesmo entendendo que a organização dos partidos implica uma relação associativa para alcançar um objetivo de maneira planejada, como Weber (1999) aponta, isso não significa que os agentes que integram o partido realizem todas as suas ações de maneira consciente e planejada. Ao contrário, muitas das suas ações são guiadas pelos habitus, como indica Bourdieu, como um processo de incorporação não consciente das estruturas, o que não implica, porém, uma postura passiva dos agentes. De fato, Bourdieu aponta que "queria colocar em evidência as capacidades ativas, inventivas, 'criadoras', do habitus e do agente (que o termo hábito não exprime)”. Com efeito, o processo de incorporação não consciente, que é seu caminho para sair da filosofia da consciência, não pode "anular o agente em sua verdade de operador prático de construções do real" (BOURDIEU, 1996A, P. 205-206). Dito de outra forma, o partido tem uma agenda, objetivos, que busca atingir de forma planejada, mas o partido é constituído de indivíduos, sendo que a ação desses nem sempre é inteiramente consciente. Com essa ressalva é que o conceito de Weber de partido se adequa ao trabalho.

Além de resgatar os conceitos de movimentos sociais e partidos políticos, trata-se de situar a emergência da reflexão acerca da relação entre esses agentes, recuperando o debate entre Rosa Luxemburgo e Lenin acerca da espontaneidade do movimento e da direção consciente do partido a propósito da criação de condições históricas para o desencadeamento de greve de massas. $\mathrm{O}$ argumento central de Rosa Luxemburgo é o de que esta é uma forma da luta de classes, que nasce a partir das relações sociais existentes na sociedade (JINKINGS-SADER, 2012), e, portanto, não pode ser decidida artificialmente, enquanto Lênin destacava que a deflagração de uma greve dependia de condições objetivas (as condições históricas) e das condições subjetivas - a propaganda e o trabalho ativo do partido. Luxemburgo enfatizava as condições objetivas, e Lenin enfatizava o papel educador do partido. Rosa Luxemburgo expressa que:

No que se refere à aplicação prática da greve de massas na Alemanha, sobre isso a história decidirá, assim como decidiu sobre ela na Rússia, história na qual a social-democracia, com suas decisões, sem dúvida, é um fator importante, mas apenas um fator, entre muitos. (JINKINGS-SADER, 2012, P. 222).

Logo, não é que ela descartava a importância do partido, mas que esse era um fator importante. Já para Lenin, mais do que um fator, o partido tinha um papel educador, quando expressou

Recordemos ao leitor esta verdade por todos conhecida, mas constantemente esquecida, e comparemos o partido social-democrata com uma grande escola, ao mesmo tempo 
elementar, secundária e superior. Nunca, em circunstância alguma, esta grande escola poderia esquecer a necessidade de ensinar o a-bê-cê, de transmitir os rudimentos do conhecimento e de criar o hábito de pensar por conta própria. (LENIN, 1979, P. 36).

Esse debate é visto em mais detalhes em Jacobina (2016). Além desses conceitos, foi importante no desenvolvimento do trabalho a incorporação da noção de "memória dividida" (PORTELLI, 1996, P. 105), discutida por Alessandro Portelli no texto ' $O$ massacre de Civitella Val di Chiana (Toscana, 29 de junho de 1944): mito e política, luto e senso comum'. Portelli cita Giovanni Contini, que descreveu a ideia de 'memória dividida', evidenciando como uma série de acontecimentos pode ter diferentes interpretações ou valorização pelos que dela participaram. A memória construída por cada grupo também difere, não apenas entre grupos, mas ao longo do tempo, no mesmo grupo de indivíduos ou na mesma comunidade, tendo o próprio tempo um efeito mediador sobre a memória.

\section{A criação do Cebes e o papel da revista 'Saúde em Debate' na RSB}

A criação do Cebes ocorreu em julho de 1976, durante a XXXII Reunião Anual da Sociedade Brasileira para o Progresso da Ciência (SBPC), realizada na Universidade de Brasília (UnB), em uma conjuntura marcada pelo esgotamento do 'milagre econômico' e pelo enfraquecimento do regime militar, processo que se dava pela via eleitoral, com o crescimento do MDB. O resgate da memória de militantes históricos da entidade registra a seguinte apreciação da conjuntura da época e destaca o significado da criação do Cebes e da publicação da RSD, veículo difusor das ideias do movimento sanitário:
Em meados de 1970 já se faziam anunciar os primeiros sinais de esgotamento do regime militar com o fim do chamado milagre brasileiro e as consequências da crise do petróleo de 1973, que elevou a inflação a níveis muito altos comparados ao período anterior: de 2,4\% na década de 1960 passou para 7,1\% nos anos de 1970. A insatisfação no campo econômico e a ressaca dos 'anos de chumbo' da ditadura, com vítimas em quase todos os setores da sociedade, constituiu o substrato para a emergência de movimentos contestatórios e culturais transgressores nas artes e na ciência. É nesse caldo que nasce, em 1976, a revista Saúde em Debate, com o propósito de ser um meio para divulgar o pensamento crítico sobre a evolução histórica e a forma institucional da saúde; interpretar a íntima relação existente entre a saúde, a lógica social de poder e os movimentos de resistência e ser um espaço democrático para divulgar novos ideais sobre saúde, originadas desse emergente pensamento no Brasil e no continente latino-americano. (AMARANTE; RIZZOTO; COSTA, 2015, P. 2024).

Além da editoração da RSD, o Cebes promoveu encontros e seminários, publicou vários livros, funcionando como um centro aglutinador do pensamento crítico que se gestava no espaço acadêmico, com funções intelectuais e também políticas. A caracterização do Cebes como um espaço de resistência e difusão de um pensamento emergente, não somente brasileiro como latino-americano, que relaciona saúde e poder, é aspecto importante para entender o papel da revista, que, ao mesmo tempo que divulgava um pensamento crítico referente às questões de saúde, assumia um papel crítico com relação à ditadura.

O trabalho de Sophia (2015), dedicado à análise da atuação da entidade nesse período, registra que a criação do Cebes contou com participação de militantes do PCB que atuavam profissionalmente em instituições acadêmicas, como docentes ou 
alunos de cursos de graduação e pós-graduação na área de saúde. Uma entrevista concedida pela médica Rosa Barros ao Projeto Memória e a História da Atenção Básica em São Paulo (PAULA ET AL., 2009), em abril de 2007, permite que se identifiquem alguns desses militantes:

No início dos anos 1970 havia discussão sobre a saúde no Partido Comunista Brasileiro, já um tanto amadurecida, exigindo das lideranças partidárias uma posição incisiva sobre a atenção à saúde da população. Vindo do Rio de Janeiro, David Capistrano da Costa Filho [1948-2000], um jovem pediatra, procurou formação na especialidade sanitarista com Sergio Arouca, então professor de Medicina Preventiva e Social na Faculdade de Ciências Médicas da Universidade de Campinas (Unicamp) e coordenador de um Projeto docente-assistencial, no município de Paulínia, base de apoio aos residentes da cadeira de medicina preventiva. David Capistrano, José Ruben de Alcântara Bonfim, José Augusto Cabral de Barros, Roseli Ziller de Araújo (residentes em 1974) e Francisco Campos (residente em 1975) e outros residentes com os quais fiz amizade, levaram-me, como sextanista de medicina, a participar de inúmeras rodas de discussões, na Unicamp, tendo o próprio Arouca como um dos grandes problematizadores do debate sobre saúde no Brasil. (PAULA ET AL, 2009, P. 150).

O grupo que viria formar o Cebes se encontrou na reunião da SBPC em Brasília, atraindo pessoas de São Paulo e do Rio de Janeiro. Como destaca Escorel, "muitas delas vinculadas ao Partido Comunista Brasileiro (PCB)" (ESCOREL, 1998, P. 75). De fato, alguns dos militantes mais importantes - como David Capistrano, cujo pai era dirigente do PCB - tinham filiação ao PCB (SOPHIA, 2015). Arouca, um dos sanitaristas mais respeitados, "[...] construiu sua identidade política com base na experiência que teve como militante do Partido
Comunista Brasileiro (PCB)" (SOPHIA, 2015, P. 96). Este último, em entrevista concedida a Escorel, indica que a articulação começou com o grupo de São Paulo, sinalizando a importância da criação de uma entidade nova:

Para trabalhar esse novo momento político que estava começando para a sociedade brasileira, era fundamental ter uma instituição que começasse de uma forma ampliada um debate das questões políticas de área da saúde [...]. Já na assembleia final da SBPC começamos a colocar a questão da política da saúde. É a partir disso que, principalmente, o grupo de São Paulo, faz a proposta de criação do Cebes. (AROUCA,1986 APUD ESCOREL, 1998, P. 75).

A leitura dos depoimentos selecionados indica que a criação do Cebes se confunde com a ideia de se fundar a RSD, sendo a entidade e a revista duas partes de um mesmo projeto. Conforme Rosa Barros,

[...] assistimos à articulação dos colegas, liderados por David Capistrano da Costa Filho, em torno da ideia de criar uma revista que discutisse a temática Saúde e Democracia, traçando um caminho para novas conquistas sociais. (BARROS, 2007 APUD PAULA ET AL., 2009, P. 152).

Como assinala Paulo Amarante, em depoimento concedido ao Projeto Memória...

[...] os jovens profissionais da saúde que formularam a ideia da revista pensavam num instrumento de debate, de reflexão e de construção de um pensamento original em saúde que viesse a questionar a política nacional do neodesenvolvimentismo liberal, própria da elite militar. Não se tratava apenas de questionar a política de saúde, na medida em que, em última instância, esse campo era entendido como um dos mais expressivos indicadores da forma como o Estado lidava com a vida das pessoas. Era o modelo de Estado burocrático autoritário que estava em questão. 
[entretanto], [...] para circular, a revista necessitava de uma entidade jurídica que lhe desse respaldo legal. Assim nasceu o Cebes, um sujeito coletivo que, desde então, responde pela sua direção política e intelectual. Um caso original na história, no qual não foi a entidade que criou um veículo de divulgação, mas a revista que deu origem ao movimento social. [...] na práxis não se observou uma distinção entre a revista e o Cebes, mas uma complementariedade (sic) de estratégias e metas. (AMARANTE; RIZZOTO; COSTA, 2015, P. 2024).

A criação da entidade propiciou, assim, o espaço necessário para a articulação de um conjunto de ações políticas, que passaram a ser desenvolvidas junto a outras organizações, como associações e sindicatos da área de saúde, problematizando-se a relação da saúde com a luta pela democracia. O depoimento de Rosa Barros elucida como se dava a atuação do Cebes, nesse momento, marcado, fundamentalmente, pelo esforço de mobilização:

O Cebes na verdade era a parte visível, era a parte que podia ser mostrada, mas por trás existiam as reuniões, as discussões dos sanitaristas para conquistar os sindicatos, existiam reuniões, e tinha esse grupo de sanitaristas que regularmente se encontrava num bar-restaurante [...] quase toda noite; também todas as sextas-feiras esse grupo de sanitaristas se reunia para discutir quais deveriam ser os encaminhamentos para assegurar essa reforma sanitária. (BARROS, 2007 APUD PAULA ET AL., 2009, P. 152).

Durante os primeiros anos de atuação, o Cebes promoveu a discussão das políticas de saúde e divulgava a ideia de que uma reforma sanitária não deveria ficar restrita apenas à reforma de serviços, à reorganização adminis-trativa do setor, mas implicava a ampliação do conceito de saúde, a noção de saúde como direito, a defesa da participação social e a conquista da democracia. $\mathrm{O}$ editorial da primeira revista do Cebes, publicada no final de 1976, reconhece a existência de outras revistas da área da saúde, porém, entende que existe uma lacuna a ser preenchida pela RSD, que é o debate em torno dos determinantes sociais do processo saúde-doença, que atribui não apenas a fatores biológicos as causas do adoecimento, mas inclui fatores sociais, econômicos e culturais, assim como determina as possibilidades de acesso a serviços de saúde pelos diversos segmentos da população (CEBES, 1976). Além disso, o editorial defende a pluralidade de posicionamentos e propostas de intervenção sobre a realidade de saúde, enfatizando a perspectiva apresentada no discurso da oradora do primeiro curso de Especialização em Saúde Pública da Faculdade de Saúde Pública da USP (CEBES, 1976). A fala referida é de Sandra Roncali Mafezolli, que fez parte do conselho editorial da RSD em 1976-1977, que questiona a eficácia de ações isoladas, concentradas no setor saúde, e afirma:

Modificações profundas na saúde do nosso povo estão na dependência de alterações significativas no modelo de desenvolvimento econômico e social em vigor, que permitam a maior parte dos brasileiros o acesso aos frutos do crescimento da produção. Tais alterações incluem necessariamente condições favoráveis à ampla participação popular na definição dos rumos do país. (CEBES, 1976, P. 8).

Conectar a saúde à questão do modelo de desenvolvimento, apresentando uma crítica ao capitalismo, e defendendo a ampla participação popular no processo de redemocratização é algo que supera uma visão meramente instrumental da democracia. Nessa perspectiva, a noção de direito à saúde aparece como contraponto à mercantilização, à subordinação da produção de serviços de saúde às leis de mercado, inspirando-se nas democracias ocidentais que universalizaram o acesso a ações e serviços de saúde. Diz a oradora 
A intervenção governamental no campo da saúde, nos países ocidentais, tem um forte conteúdo social, na medida em que trata de enfraquecer ou mesmo suprimir, para os contingentes populacionais menos favorecidos, as frias relações de mercado que determinam a possibilidade de compra de todos os bens e serviços, inclusive os de saúde, considerados eticamente como um direito de todos e não um privilégio de alguns. (CEBES, 1976, P. 8).

O que mais nos chama a atenção é a noção de 'combate à mercantilização da medicina'. Fica evidente que a crítica à penetração da lógica da produção capitalista na saúde, especialmente à transformação dos serviços em mercadoria, termina por ser um veículo à crítica ao capitalismo nacional, ou ao 'modelo de desenvolvimento vigente'. O fato de que, naquele período, a censura e a repressão ainda estavam presentes, mesmo que em menor intensidade do que nos 'anos de chumbo', provavelmente, contribuía para que determinadas palavras fossem evitadas, utilizando-se de subterfúgios para a expressão das ideias. Porém, nessa fala de Sandra Roncali, que a RSD destacou, percebe-se um esforço para deixar clara a posição do grupo do qual ela, naquele momento, era porta-voz.

O editorial da segunda publicação da RSD critica as novas modalidades de prática médica, especialmente as empresas médicas, "cujo produto a vender é assistência médica”, enfatizando que estas estariam impondo sua visão ao conjunto dos profissionais. O trecho a seguir evidencia este ponto de vista:

O grupo ligado aos interesses das empresas médicas, fortemente organizado e influente, apesar de minoritário entre os profissionais, obtém apreciáveis recursos, advindos de descontos na remuneração de milhões de assalariados, por meio do INPS, para manter em funcionamento, hospitais e clínicas privados, 'empresas de medicina de grupo', pseudocooperativas, responsáveis por práticas condenáveis, como decorrência da sede de lucros. Assalariou milhares de médicos, de fato, negando-lhes, entretanto, os direitos que os demais assalariados já conquistaram no país. (CEBES, 1977, P. 3).

Depois de caracterizar outras posições, o editorial se posiciona no que tange ao assalariamento, porém, e aí nos interessa especialmente, já anuncia a defesa de um sistema nacional de saúde que fosse público e universal, materializando o direito à saúde de todos os brasileiros.

Em vez do apego a práticas médicas, provindas de outra época histórica, adotamos o novo modo de ser, o assalariamento, propondo uma luta para torná-lo honrado, digno e útil à população. Assalariados, mas com direitos trabalhistas atendidos, com salário condigno, com a consciência de que a medicina de lucro impede a organização de uma assistência médica racionalizada e adequada à população. Assalariados com disposição de lutar por um Sistema Nacional de Saúde, público, institucional, sem fins lucrativos, cuja definição e rumos sejam dados pelas entidades legitimamente representativas dos usuários. Esta é a única posição que, como escreveu respeitada socióloga 'implica na recomposição, em outro nível, da identidade entre profissional e trabaIhador'. Ou seja, que é capaz de conciliar as exigências éticas fundamentais da profissão com a elevação do nível de saúde da população, e com o preceito, também ético, e com o qual nos identificamos, de que a saúde é um direito de cada um e de todos os brasileiros. (CEBES, 1977, P. 3-4).

Pelo exposto, entende-se que a RSB, em sua concepção original, tinha como eixo central a luta pela democracia, ao qual se articulava a crítica à política de saúde implementada pelo Estado autoritário, que privilegiava o processo de privatização dos serviços e reproduzia um modelo de 
1 A entrevista com Reinaldo Guimarães, originalmente, foi feita por Ligia Vieira da Silva, porém, entramos em contato com o entrevistado para conseguir

informações adicionais via e-mail. Esse trecho corresponde, justamente, a parte das informações adicionais passadas para mim em contato via e-mail com o entrevistado, que autorizou seu uso em publicação. atenção que excluía grande parte da população do acesso às ações e aos serviços necessários à promoção e à recuperação da saúde. Tais ideias amadureceram ao longo da segunda metade dos anos 1970 e aparecem claramente explicitadas no documento 'A questão democrática na área da saúde' (FLEURY; BAHIA; AMARANTE, 2007, P. 149-151), redigido por Hésio Cordeiro, José Luís Fiori e Reinaldo Guimarães (Guimarães, entrevista 2010), cuja apresentação no Simpósio sobre Política de Saúde, realizado na Câmara dos Deputados, em 1979, marca o momento em que a proposta de RSB começa a extrapolar o espaço da saúde no âmbito da sociedade civil e insere-se no espaço político do Estado.

Segundo entrevista concedida à nossa pesquisa, pelo menos dois dos três redatores desse documento histórico eram vinculados ao PCB, o que levou à análise se a noção de 'saúde como democracia' traduzia a tática do PCB para aquela conjuntura ou era a forma com que militantes da RSB, que eram do $\mathrm{PCB}$, colocavam essa questão do partido para a luta no movimento. Cabe acrescentar que a ênfase na democracia era uma palavra de ordem e opção tática do PCB, sendo compartilhada por outros partidos de esquerda e diversos segmentos liberais que compunham a frente contra a ditadura. Isso pode, entretanto, ter ocorrido de forma não consciente e não ditada pela direção dos partidos.

Um dos nossos entrevistados reforçou a perspectiva de que essa ideia não partiu da direção do partido e que sua participação se dava através daqueles que tinham dupla militância, isto é, eram filiados ao partido e, simultaneamente, ao movimento sanitário:

\section{[...] o PCB não tinha uma posição orgânica so-} bre a RSB. Sua participação no processo derivava da participação de seus militantes no campo da saúde. O documento foi solicitado a nós por Sérgio Arouca para servir de âncora político-documental no seminário sobre a reforma sanitária realizado na Câmara dos Deputados. (Reinaldo Guimarães, contato posterior à entrevista em 2016)1.

Buscando investigar mais a fundo os diversos pontos de vista acerca da relação entre o Cebes e os partidos de matriz marxista, especialmente o PCB, partido apontado como aquele ao qual eram filiados vários dos fundadores da entidade, foram procurados nas entrevistas já publicadas e nas realizadas com ex-presidentes do Cebes trechos que elucidassem essa relação.

Antônio Sergio Arouca, uma das maiores lideranças da RSB e militante do PCB, ao caracterizar o movimento sanitário, destaca o papel do PCB:

[Era] um movimento social de luta contra a ditadura [...] um movimento social muito amplo. 'Ele envolvia o Partido Comunista, que tinha um papel central. Era o partido que mais tinha organização e pessoas na área de saúde, a Igreja, os movimentos de base da Igreja, os movimentos sociais comunitários, os movimentos de renovação do sindicalismo na área profissional de saúde. Começaram a tirar pelegos, começaram a discutir uma nova forma de sindicalismo'. (ALVES ET AL., 2002, P. 7-8).

Outra liderança histórica do movimento, Francisco de Assis Machado, que exerceu a presidência do Cebes, discorre, como segue, sobre sua participação como militante no PCB:

Minha experiência como membro oficial do PCB marcou profundamente minha vida e, de certa forma, a de toda minha família. Reencontrei no convívio com camaradas 'calejados' e orgulhosos de seus passados, bem como naquele com os jovens recémorganizados, o "eu" coletivo que passou a ajudar-me nas reflexões e preparações para práticas mais coerentes e consequentes na construção de uma sociedade mais justa. Ali, consegui compreender melhor o sentido do agir de grandes companheiros e lideranças do 
Movimento pela Reforma Sanitária Brasileira, que procuravam estabelecer a unidade de seus objetivos como profissional e como sujeitos políticos: a inclusão ou, talvez melhor, a substituição do grande Objetivo que até então perseguia, o construção de um Sistema de Saúde eficiente, democrático e justo, por um outro que era condição para seu alcance e que teria de ser atingido com urgência: o estabelecimento da democracia política no País. (MACHADO, 2014, P. 316).

Outra entrevistada, cientista social de grande relevância para a $\mathrm{RSB}$ e para $\mathrm{o}$ Cebes, que era filiada ao PCB, traz diversos elementos que apontam a relação entre o movimento e o partido, enfatizando a contribuição que este teria, segundo seu ponto de vista, para a organização do movimento. A pergunta que gerou a reflexão da entrevistada sobre essa questão era relativa a gostos culturais comuns entre os militantes da RSB, interrogando-se até que ponto isso contribuía para reuni-los, em termos de convivência, ou se era a própria questão política da RSB que preponderava como ‘elo de ligação’ entre eles. Ao que a entrevistada explicitou:

Eu penso que era política, a grande coisa que nos unia era a política. A gente saía do Cebes - a reunião do Cebes era no centro da cidade, no sindicato dos médicos - e, depois disso, a gente ia, todo mundo, para o 'Amarelinho'2. Então, todas as reuniões terminavam com grande confraternização, era uma coisa muito legal isso. [...]. Era, assim, muito forte, essa ligação que nós tínhamos. As pessoas se namoravam umas às outras, tinha grandes identidades ali. O grupo era muito próximo, muito afetivo, havia muita solidariedade entre essas pessoas também. Eu acho que a experiência, a ligação dessa reforma com o partido comunista, eu faço muita questão de ressaltar, porque acho que é pouco ressaltada, e eu penso que a experiência de solidariedade, de organicidade do partido, foi fundamental. Sem isso, esse negócio não tinha dado certo, porque tinha que saber fazer política, e o partido sabia fazer'. Então, acho que foi fundamental, por exemplo, o papel de liderança do Arouca para nos congregar e a experiência do partido para dar organicidade' a tudo isso. (E8).

Um ex-presidente do Cebes, que militou não apenas no PCB, mas, antes disso, na Ação Popular, apresenta, como segue, seu ponto de vista sobre essa relação:

Não era formalmente militante do $P C B$ entre 1976 a 1979, só ingressando nele depois, mas não havia subserviência do Cebes em relação ao $P C B$, uma vez que a entidade sempre foi independente, e entre seus integrantes existiam militantes de diferentes correntes da esquerda. Creio que houve uma intensa troca de ideias, mas, em muitos momentos dos primeiros tempos do $\mathrm{Ce}$ bes, houve certa predominância de dirigentes da entidade que eram membros do PCB. A partir de 1982, com a reorganização partidária legal, houve plena liberdade de escolha de filiações, que, no entanto, não prejudicaram a continuidade do Cebes. (E27).

Outra entrevistada, também ex-presidente do Cebes, comenta acerca da relação da entidade com o PCB, destacando a contribuição da experiência partidária das lideranças para a organização das ações do movimento:

Na medida em que essa indignação, esse sentimento passa a se configurar como uma bandeira e ser instrumentado por uma luta como movimento da Reforma Sanitária, é que o partidão, que o partido comunista passa a ter protagonismo. Que mobilizavam mais e que tiveram a inteligência estratégica conformando e organizando, sistematizando esses pensamentos, eram do partidão, não só o Arouca, o Eleutério, mas, também, a própria Cecília Donnangelo, aqui, o 'Chico Gordo', Francisco Campos, então [...], já existia uma forte presença do partidão. [...] é uma pena que, naquele momento, havia uma tensão entre os demais grupos do campo de esquerda e o partidão.

\footnotetext{
2 Bar situado no centro do Rio de Janeiro, ponto de encontro de intelectuais, artistas e pessoas ligadas aos movimentos de oposição à ditadura militar.
} 
3 Anos 1980, o Partido dos Trabalhadores (PT) desloca o Partido Comunista (PC) na área da saúde, reforça a tese de que militantes do PCB que não se identificavam com as mudanças migraram por exemplo, para o PT.

4 Duas visões sobre a Abrasco: uma que pensa em uma associação de militantes da área da saúde; e outra em uma instituição de pesquisa. A proposta dos militantes, derrotada, o possível morto, era Associação Brasileira de Saúde Coletiva.
Essa tensão existia [...] na 8ª Conferência Nacional de Saúde, por exemplo, houve um confronto real em relação a estatiza tudo agora ou estatiza depois... (Entrevistada 7).

Essa entrevista é particularmente importante, pois aponta, além do significado atribuído pela entrevistada à participação de militantes filiados ao PCB na organização do movimento, a constatação das tensões que prevaleciam no 'campo da esquerda', ou seja, das opções políticas e estratégicas adotadas pelas lideranças do movimento sanitário, que priorizavam a luta pela democracia e pelo Estado de direito, com outras correntes de esquerda que também atuavam no campo político nos anos 1970-80. Essa análise, entretanto, extrapola os limites deste trabalho, demandando pesquisa em fontes adicionais que deem conta da complexidade das relações entre o movimento sanitário e outras organizações e partidos políticos.

Por fim, uma das poucas evidências de influência mais direta é o episódio do 'racha' no Cebes de São Paulo, narrado por Paulo Elias, médico, professor universitário e militante da RSB, a propósito da criação da Abrasco, que revela como o envolvimento dos militantes da RSB com os partidos afetava as disputas relacionadas com as entidades que se propunham a ser suprapartidárias:

Então, tinha duas concepções básicas que eu me recordo muito bem. Uma era uma Associação de Militantes, que era uma ampliação dos [...], o Cebes, que tinha sido concebido e criado como... uma coisa assim numa certa época ele foi isso, ele teve um racha muito intenso. Em São Paulo, por exemplo, 'quem não era do Partido Comunista foi expulso [...]. Ali, teve um racha que teve até briga física entre o David Capistrano e o Eduardo Jorge numa assembleia no Cebes'. Toda essa ala saiu, toda uma ala saiu. Eu estava na revista Saúde em Debate, tinha Cecília Sucupira, todo mundo foi excluído - aquela coisa como lá na
União Soviética. Excluídos do Cebes e esse pessoal, grande parte dele se encontrou depois no PT. (Paulo Elias, em entrevista, 2010).

E, mais adiante, quando indagado por qual razão, respondeu:

Na época, tentaram baixar um centralismo no Cebes. A briga era isso... Eram anos [...] setenta e sete, setenta e oito. A briga em relação ao que é reformismo... A briga começou por aí [...] Eu sempre falo isso, 'que o agente oculto do movimento da Reforma Sanitária no Brasil foi o Partido Comunista'. Então, [...] a briga foi um pouco por aí, quer dizer, quem não era, dançou, porque tinham essas visões. Foi um racha, e que pegou, em São Paulo, e dizimou, no Rio de Janeiro. Isso não aconteceu muito porque ele era muito hegemonizado pelo PC, depois o PT deslocou o PC da área da saúde, mas, nessa época, o PC era hegemônico na área da saúde. 'O PT começou a deslocar o PC da área de saúde na década de oitenta, mas antes não tinha nem o que acontecer, então, isso aconteceu mesmo, rachou, na época da $\mathrm{Abrasco}^{\prime 3}$. O que eu me lembro é o seguinte: tinham duas concepç̃es, ou fazer uma Abrasco que seria um Cebes revigorado com uma espécie de um grande, não vou dizer um sindicato, mas uma Associação de militantes da área da saúde, e uma visão que era acadêmica, 'que a Abrasco deveria ser uma instituição de pesquisa, de desenvolvimento, implantação da área'4. Isso confrontou pesadamente, só que venceu esta, tanto é que a Associação Brasileira de Pós-graduação em Saúde Coletiva, os outros queriam Associação Brasileira de Saúde Coletiva, onde caberiam todos. Caberia à Universidade, sem dúvida, mas a grande massa seriam os funcionários públicos, vamos dizer assim, que era a grande plateia, como é até hoje a da Abrasco. Seriam funcionários dos três níveis de governo, e eu me lembro que um defensor intransigente dessa primeira visão da Associação Brasileira de Saúde Coletiva era o Chico Gordo. Contra ele se opunha muita gente: Professor Guilherme, por exemplo. Tinham outros que ficavam meio em cima do muro. (Paulo Elias, em entrevista, 2010). 
Já na percepção de Gastão Wagner, não teria havido expurgo, e, sim, disputa pelo controle da direção do Cebes entre o PCB e a Ação Popular Marxista Leninista (APML):

Recentemente, Emerson Merhy escreveu uma carta - e-mail - para José Ruben narrando esse racha no Cebes São Paulo, em finais dos anos setenta e começo dos oitenta. Não houve expurgo nem expulsões. Isso foi exagero do Paulo Elias. Houve uma divisão, e concorreram duas chapas, uma organizada por David Capistrano e o pessoal do PCB, mais aliados; e outra pelo pessoal pertencente à então $A P M L$, liderados pelo Emerson. A chapa do David ganhou por pequena diferença, e o grupo dissidente se afastou do Cebes. Foi uma luta por controle de aparelho, no caso, o Cebes. Não havia grandes diferenças de projetos. (Gastão Wagner, entrevista em 2014)5.

Novamente, mesmo que se aceite o ponto de vista de Gastão Wagner, que indica não ter havido uma expulsão, e, sim, uma saída motivada pela derrota sofrida por um determinado grupo na disputa pelo poder, pela direção do Cebes, a disputa está evidente. Trata-se de uma disputa político-partidária entre o grupo que militava na APML e os agentes vinculados ao $\mathrm{PCB}$, ambos disputando a direção do Cebes.

\section{Considerações finais}

As informações apresentadas e analisadas neste trabalho, colhidas de diversas fontes, principalmente entrevistas com militantes do Cebes, ex-dirigentes da entidade, revelam a importância da experiência adquirida através da filiação ao PCB, ou 'partidão', no momento de emergência do movimento pela RSB. Quer pelo fato da inserção nas fileiras do partido ter sido o acontecimento que proporcionou o questionamento e a problematização da realidade brasileira na época da ditadura militar, quer pelo fato da militância no partido ter propiciado o aprendizado do 'fazer política', vários dos entrevistados que admitiram essa dupla militância enfatizaram a importância do habitus adquirido no campo 'político-partidário'. Era o 'saber fazer política' essa habilidade, disposição adquirida no partido, que foi aplicada na militância do movimento sanitário.

Por outro lado, vários dos entrevistados apontam que o PCB e outros partidos de matriz marxista não chegaram a exercer uma ingerência sobre o movimento sanitário. $\mathrm{Ou}$ seja, não provinham da direção do partido as orientações políticas e estratégicas para a organização e a atuação do movimento, podendo-se constatar a existência de certa autonomia das lideranças que atuavam no movimento sanitário com relação à direção do partido. O PCB e os demais partidos e tendências de matriz marxista foram importantes na formação das lideranças, porém, a dimensão suprapartidária do movimento parece ser verdadeira, pois a RSB também congregou pessoas sem filiação e de diferentes filiações. Isso não significa, entretanto, que os partidos tiveram uma importância desprezível, apenas confirma a complexidade do processo da RSB, enquanto um movimento, simultaneamente, de composição e de ideais suprapartidários, que teve, especialmente em seu início, grande presença de lideranças ligadas a partidos de matriz marxista, em especial, o PCB. Essa ligação, longe de gerar um direcionamento do partido ou uma cooptação do movimento pelo partido, gerou, de forma predominante, uma contribuição do partido, através das lideranças da Reforma Sanitária, que aplicaram os conhecimentos adquiridos na militância partidária na luta por uma sociedade mais democrática e mais igualitária.

Para finalizar, cabe registrar que este trabalho representa uma pequena contribuição ao debate, que remonta à polêmica entre Lênin e Rosa Luxemburgo (JACOBINA, 2016), sendo que a questão central é a dicotomia 'direção consciente' $\mathrm{x}$ 'espontaneismo'
5 Embora a entrevista tenha ocorrido em 2014, as informações sobre essa questão foram prestadas em 2015, em um contato subsequente especificamente sobre o racha. 
da ação das massas. Essa dicotomia, longe de ficar restrita à análise do processo que conduziu à revolução russa de 1917, permeia os trabalhos que analisam a relação entre partidos e movimento. Em nosso estudo, a relação entre o Cebes e o PCB nem se apresenta como 'direção consciente' do partido sobre a entidade, nem evidencia uma 'autonomia' plena da entidade com relação ao partido, na medida em que a presença do partido na vida e na ação política de várias das lideranças históricas do movimento sanitário foi um elemento objetivo que influenciou a subjetividade dos agentes que se engajaram na luta pela democracia e pela RSB. Com isso, é possível compreender a diversidade de pontos de vista presente nas fontes acerca da emergência do movimento sanitário e, particularmente, sobre os elementos que influenciaram a ação política do Cebes, configurando um espaço de pontos de vista que valorizam, de um lado, a influência do PCB e de outros partidos de matriz marxista e, de outro, o ponto de vista de agentes que consideram que a atuação da entidade foi suprapartidária, minimizando, portanto, a influência dos partidos.

O nosso ponto de vista, baseado nas evidências analisadas na tese (JACOBINA, 2016), das quais uma pequena parte é apresentada neste artigo, é o de que se trata de uma dupla verdade (BOURDIEU, 1996B, P. 85). Os partidos de matriz marxista, por serem um espaço de aprendizado do "saber fazer" política, tiveram um papel central na trajetória de muitas das lideranças da RSB e, assim, tiveram influência indireta sobre o Cebes, já que aqueles que tinham dupla militância (PCB e Cebes) levaram essas experiências para sua prática.

Simultaneamente, a atribuição de uma dimensão suprapartidária à atuação do Cebes é verdadeira, não apenas como um ideal de autonomia, que estava profundamente presente na fala dos militantes da $\mathrm{RSB}$, mas como uma realidade, pelo fato do movimento e do Cebes, enquanto entidade orgânica à RSB, congregarem pessoas de múltiplas filiações e sem filiação partidária. Nesse sentido, a autonomia se refere ao fato de, aparentemente, os partidos terem tido pouca ingerência no dia a dia das entidades e na prática da militância, na medida em que, embora haja algumas evidências de que, em determinadas circunstâncias, houve influência mais direta, destaca-se aqui o episódio do 'racha' em São Paulo. Essas que foram examinadas na tese (JACOBINA, 2016) nos pareceram insuficientes para afirmar uma direção consciente, embora essa hipótese não possa ser afastada, necessitando de mais estudos.

A importância da experiência nos partidos marxistas para a vida de grande parte dos militantes, para sua experiência política, é algo perceptível e relevante na história do Cebes, e ficou evidente no exame das entrevistas, a partir do momento em que essa experiência partidária se tornou um saber que contribuiu, especialmente, na emergência do movimento sanitário para a definição das estratégias de luta pela RSB. Ela é parte da História dessa luta, e, por isso, deve ser lembrada. 


\section{Referências}

AMARANTE, P.; RIZZOTTO, M. L. F.; COSTA, A. M.

Memória de um movimento: a revista Saúde em Debate e a reforma sanitária brasileira. Ciênc. saúde coletiva, Rio de Janeiro, v. 20, n. 7, p. 2023-2029, jul. 2015.

ALVES, Z. et al. Doutor democracia: entrevista com Sergio Arouca. O pasquim 21. Rio de Janeiro, n. 27, ago. 2002.

BOURDIEU, P. As regras da arte. São Paulo: Companhia das Letras, 1996a.

Razões práticas: sobre a teoria da ação.

Campinas: Papirus, 1996b.

\section{CENTRO BRASILEIRO DE ESTUDOS DE SAÚDE}

(CEBES). O cenário depois do golpe. Saúde debate, Rio de Janeiro, n. 1, p. 5-8, 1976.

Editorial. Saúde debate, Rio de Janeiro, n. 2, p. 3-4, 1977.

Prev-saúde. Saúde debate, Rio de Janeiro, n. 12, p. 21-25, 1981.

A questão democrática na área da saúde. Saúde debate, Rio de Janeiro, n. 9, p. 11-13, 1980.

A saúde em debate nas eleições presidenciais: memória e perspectivas. Saúde debate, Rio de Janeiro, v. 34 , n. esp., set. 2010.

Editorial. Saúde em Debate, Rio de Janeiro, n. 2, p. 3-4, 1977.

ESCOREL, S. Reviravolta na Saúde: origem e articulação do movimento sanitário. Rio de janeiro: Fiocruz, 1998

ESCOREL, S.; NASCIMENTO, D. R.; EDLER, F. C. As origens da reforma sanitária e do SUS. In: LIMA, N. T. et al. (Org.). Saúde e democracia: história e perspectivas do SUS. Rio de Janeiro: Fiocruz, 2005, p. 59-81.
FLEURY, S.; BAHIA, L.; AMARANTE, P. Saúde em debate: fundamentos da Reforma Sanitária. Cebes: Rio de Janeiro, 2007.

JACOBINA, A. T. O movimento da Reforma Sanitária brasileira e sua relação com os partidos políticos de matriz marxista. 217 p. 2016. Tese (Doutorado em Saúde Coletiva) - Instituto de Saúde Coletiva, Universidade Federal da Bahia, Salvador, 2016.

JINKINGS, I.; SADER, E. (Org.). As armas da crítica. São Paulo: Boitempo. 2012.

LENIN, V. I. Confusão entre política e pedagogia. In: Obras escolhidas em 3 tomos. São Paulo: Ciências humanas, 1979, p. 26-36.

MACHADO, F. A. O SUS que eu vivi. Rio de Janeiro: Cebes, 2014

PAIM, J. S. Reforma sanitária brasileira: contribuição para a compreensão e crítica. Salvador: EDUFBA; Rio de Janeiro: Fiocruz, 2008.

PAULA, S. H. B. et al. A criação de Saúde em Debate, revista do Cebes: narrando a própria história. Saúde debate, Rio de Janeiro, v. 33, n. 81, p. 148-155, jan. /abr., 2009

PORTELLI, A. O massacre de CivitellaVal di Chiana (Toscana, 29 de junho de 1944): mito e política, luto e senso comum. In: FERREIRA, M. M.; AMADO, J. (Org.). Usos e abusos da História Oral. Rio de Janeiro: FGV, 1996, p. 103-130

PORTELLI, A. The peculiarities of oral history. History workshop journal, Oxford, v. 12, n.1, 1981.

SOPHIA, D. C. Saúde e utopia: o Cebes e a Reforma Sanitária Brasileira (1976-1986). São Paulo: Hucitec; Sobravime, 2015.

TILLY, C. Social movements as historically specific 
clusters of political performances. Berkeley Journal of Sociology, California, v. 38, p. 1-30, 1993

VIEIRA-DA-SILVA, L. M.; PINELL, P. The genesis of collective health in Brazil. Sociology of Health \&t Illness, Boston, v. 36, n. 3, p. 423-446, set. 2013.

Gênese Sócio Histórica da Saúde Coletiva no Brasil. In: LIMA, N. T.; SANTANA, J. P.; PAIVA, C. H. A. (Org.). Saúde Coletiva: a Abrasco em 35 anos de história. Rio de Janeiro: Fiocruz; Abrasco, 2015, p. 25-45.

WEBER, M. Economia e Sociedade Fundamentos de uma Sociologia Compreensiva. Brasília, DF: UnB, 1999

Recebido para publicação em novembro de 2016

Versão final em novembro de 2016

Conflito de interesses: inexistente

Suporte financeiro: não houve 